\title{
Imaginación y creatividad matemática en las ciencias sociales
}

\author{
Enric Ramiro Roca \\ Universitat Jaume I de Castellón \\ ramiro@uji.es \\ José Vicente Gil Noé \\ Universitat Jaume I de Castellón \\ noe@uji.es
}

Fecha presentación: 23/11/2017 | Aceptación: 12/12/2017 |Publicación: 21/12/2017

\section{Resumen}

Son numerosas las críticas a una universidad que no siempre ha estado conectada suficientemente a la sociedad. También las ciencias sociales han sido motivo de desaprobación por tener la imagen de un área aburrida, inútil y memorística. $Y$ en tercer lugar, ha habido una separación tradicional entre las ciencias y las letras en un mundo cada vez más globalizado, con temas de frontera y trabajo en equipo. Es por ello, que desde el Área de didáctica de las ciencias sociales en el seno del Departamento de Educación de la Universidad Jaume I de Castellón (UJI), un grupo de profesores hemos puesto en marcha todo un conjunto de actividades y recursos para aproximar los estudios de magisterio a la realidad del aula. Y lo hemos hecho a partir de los contenidos de geografía, historia y arte para favorecer una metodología más activa e innovadora en el área de conocimiento del medio y de cultura valenciana.

Las formas que han adaptado los nuevos recursos han sido diversas como barajas de cartas, juegos de mesa y posters. En todos ellos hemos relacionado técnicas matemáticas a través de la matemagia con los contenidos de accidentes geográficos, personajes históricos, fiestas y tradiciones, o biografías entre otros, y utilizando las diversas tipologías textuales. Las evaluaciones realizadas, demuestran el buen clima de la clase, la autonomía conseguida por el alumnado y la utilidad de las enseñanzas y competencias conseguidas. En cambio, alumnado y profesorado participante coinciden en la intensidad del trabajo realizado, la conveniencia de aligerar la realización de actividades y la necesidad de una mayor coordinación entre los docentes de las asignaturas de un mismo grado.

Palabras clave: didáctica; interculturalidad; igualdad de género; matemagia.

\section{Resum}

Són nombroses les crítiques a una universitat que no sempre ha estat connectada suficientment a la societat. També les ciències socials han estat motiu de desaprovació per tindre la imatge d'una àrea avorrida, inútil i memorística. I en tercer lloc, hi ha hagut una separació tradicional entre les ciències i les lletres en un món cada vegada més globalitzat, $\mathrm{amb}$ de temes de frontera i treball en equip. És per això, que des de l'Àrea de didàctica de les ciències socials al si del Departament d'Educació de la Universitat Jaume I de Castelló (UII), un grup de professors hem posat en marxa tot un conjunt d'activitats i recursos per a aproximar els estudis de magisteri a la realitat de l'aula. I ho hem fet a partir dels continguts de geografia, història i art per a afavorir una metodologia més activa i innovadora en l'àrea de coneixement del medi i de cultura valenciana. Les formes que han adaptat els nous recursos han estat diverses com baralles de cartes, jocs de taula i pòsters. En tots ells hem relacionat tècniques matemàtiques a través de la matemàgia amb els continguts d'accidents geogràfics, personatges històrics, festes i tradicions, o biografies entre altres, i utilitzant les diverses tipologies textuals. Les avaluacions realitzades, demostren el bon clima de la classe, l'autonomia aconseguida per l'alumnat i la utilitat de les ensenyances i competències aconseguides. Per contra, alumnat i professorat participant coincideixen en la intensitat del treball realitzat, la conveniència d'alleugerir la realització d'activitats, i la necessitat d'una major coordinació entre els docents de les assignatures d'un mateix grau.

Paraules clau: didàctica; interculturalitat; igualtat de gènere; matemàgia.

\section{Abstract}

University has been criticized because of it hasn't been always linked enough to the society. Also, social sciences have been disapproved because they have been perceived as a boring area, unuseful and memory-based. And third, there 
Ramiro Roca, Enric; Gil Noé, José Vicente. “Imaginación y creatividad matemática en las ciencias sociales”. @tic. revista d'innovació educativa. Número 19. Otoño (Julio-Diciembre 2017), pp. 56-61.

has been a traditional separation between Science and Arts into a more and more globalized world, with border issues and teamwork. Because of that reason, from didactics of social sciences area into the education department of the University Jaume I of Castelló (UJ), a group of professors have started a set of activities and resources in order to bring near Teaching studies and the real classroom. And we have done it from contents of geography, history and art in order to favor a more active and innovative methodology in the environment knowledge and Valencian culture areas.

Resources have been adapted in different ways as a deck of cards, board games and posters. In all of them, we associate mathematical techniques through mathemagic with the contents of geographical features, historical figures, festivities and traditions, or biographies among others, and using different text typologies. The evaluations show the good climate in the classroom, the autonomy achieved by the students and the utility of the teachings and the competences accomplished. However, students and professors agree with the intensity of the work done, the convenience of lightening the activities and the need of a better coordination between professors of different subjects in the same degree.

Key Words: didàctics; interculturality; gender equality; mathemagic.

\section{De quines idees partim?}

A poc que llegim o preguntem a les nostres amistats, alumnat o veïnat ens adonarem que la majoria tenen unes determinades idees sobre les ciències socials $i$ sobre les matemàtiques que no sempre s'ajusten a la realitat.

Si parlem d'història, geografia i art, les paraules que tenen més presència són avorriment, memorisme i inutilitat en totes les seues variants. I si la qüestió l'adrecem a les matemàtiques, els mots més repetits són importants, difícils i numeració. I no es tracta tan sols de la nostra percepció, sinó de les preguntes que hem fet en els diversos cursos impartits a mestres, professors $i$ alumnes, i de forma més impersonal a aquelles persones amb les quals ens relacionem més a sovint.

Tanmateix, a poc que aprofundim en les dues àrees ens adonarem que no sempre s'ajusten aquestes idees prèvies al conjunt del seu contingut, però sí que és cert que hi ha una llarga tradició que ho justifica. La consideració d'assignatura "maria" al coneixement del medi, tant si ens agrada com si no, està ben arrelada, a l'igual que la matemàtica és una matèria important que no es pot suspendre.

Ara bé, quan aprofundim en les ciències socials, podem descobrir la geografia humanística, o la geografia de la percepció i dels comportaments, junt amb la geografia de les catàstrofes, o la història de les sensacions, la història de les minories, entre altres modalitats. Unes especialitzacions que demostren com la distància entre València i Algemesí no és la mateixa que entre Algemesí i València, o que la percepció del trajecte entre Barcelona i Nàpols pot semblar més curta que entre la capital catalana i Alger, quan no és així. I és que tots tenim els nostres mapes interiors amb independència dels atles, o que coneixem tan sols una part de la història i no sempre és correcta.

I si ho fem amb les matemàtiques, destacaríem la matemàgia, una branca de la màgia i l'illusionisme que fa servir procediments basats en propietats matemàtiques per enganyar (tot entretenint-lo) l'espectador. La majoria de jocs són automàtics i de fonaments científics, amb un divulgador central com fou Martin Gardner, autor de múltiples llibres, molts d'ells basats en la seua columna a la prestigiosa revista Scientific American. Però també tenim les illusions òptiques, la interessant etnomatemàtica o la misteriosa $\mathrm{i}$ divertida topologia matemàtica.

Amb aquesta base tan diversa i plural, hem intentat crear recursos imaginatius i innovadors per a superar la tradicional animadversió cap a les matemàtiques i fer més atractiva la visió cap a les ciències socials. El resultat ha estat un conjunt de jocs que pretenen complementar el currículum i ajudar en les diferents competències 1 . Així doncs, els nostres objectius específics passen per:

- enriquir les idees generades a l'aula,

- potenciar la creativitat i imaginació,

- provocar la sorpresa i l'emoció,

- crear un bon ambient de classe, aprendre jugant,

- aconseguir canvis d'actituds de forma subliminal,

- collaborar en al convivència i el treball cooperatiu,

facilitar la respiració davant les sessions d'ensenyament-aprenentatge,

- obrir nous camins a la investigació voluntària,

- gaudir d'unes ciències socials i matemàtiques agradables, positives, reflexives i crítiques.

I inclús ens atreviríem a dir que pot ser ajudem també a que aprenguen alguns coneixements significatius de quan en quan. El que no pretenem és crear sistemes diferents, ni fer projectes concrets, oferir alternatives incompatibles, o marcar mètodes que s'hagen de seguir amb materials concrets. Tot el contrari, són tècniques obertes i recursos que es poden adaptar a diferents nivells, situacions i contextos.

\section{Quins materials oferim?}

Tot el conjunt d'instruments que detallem a continuació tenen com a característica comuna que estan basats en les matemàtiques i que s'ofereixen per a desenvolupar continguts de ciències socials, però possiblement també es podria justificar a la inversa, i treballar diferents coneixements matemàtics utilitzant com a excusa elements de l'entorn proper.

No anem a entrar en els forts lligams entre les dues àrees com ho demostra la seua evolució històrica, però si que voldríem anotar almenys, que la matemàtica està contínuament present a la nostra vida diària i que som producte d'una història, geografia i art que ens envolta i ens condiciona (Ramiro, 2017). Cal recordar també, que la geografia com a ciència que se ocupava de la descripció i de la representació de la Terra, formava part de la matemàtica (Capel i Urteaga, 1991).

\subsection{Catàleg de recursos didàctics per a la investigació de} les ciències socials

\footnotetext{
${ }^{1}$ Aquesta investigació ha estat subvencionada parcialment per la Unitat de Suport Educatiu de la Universitat Jaume I de Castelló en les diverses convocatòries als projectes d'Innovació Educativa del 2011 al 2105.
} 
Ramiro Roca, Enric; Gil Noé, José Vicente. “Imaginación y creatividad matemática en las ciencias sociales”. @tic. revista d'innovació educativa. Número 19. Otoño (Julio-Diciembre 2017), pp. 56-61.

El marc general on incardinar la resta de materials que proposem és el catàleg que tot seguit presentem. A sovint ens hem vist en la necessitat de consultar documentació cartogràfica, estadística o documental, i hem hagut d'utilitzar temps i esforç en la recerca. Igualment, s'haurem trobat en la tessitura d'orientar sobre algun enllaç bàsic que no recordàvem en un moment determinat o recomanar algunes webs per a les oposicions, treballs d'investigació com TFGs, TFMs o simplement redaccions d'aula o estudis.

Aquest catàleg naix d'una realitat:

a) els alumnes no coneixen revistes que els seran molt útils si es dediquen a l'educació i tenen sensibilitat pel tema.

b) els alumnes d'ESO, batxillerat i universitat a sovint estan desorientats a l'iniciar un treball d'investigació com els TFG, TFM, preparació d'oposicions, redacció d'articles per a revistes, consultes per a la confecció de llibres o monografies.

c) els mestres i professors d'infantil, primària, secundària o universitat, a sovint tenen necessitat de tindre ràpidament a l'abast enllaços actuals que els proporcionen bases de dades, cartografia, adreces electròniques i més recursos que els faciliten la preparació de les classes, la realització de treballs, o orientar-los.
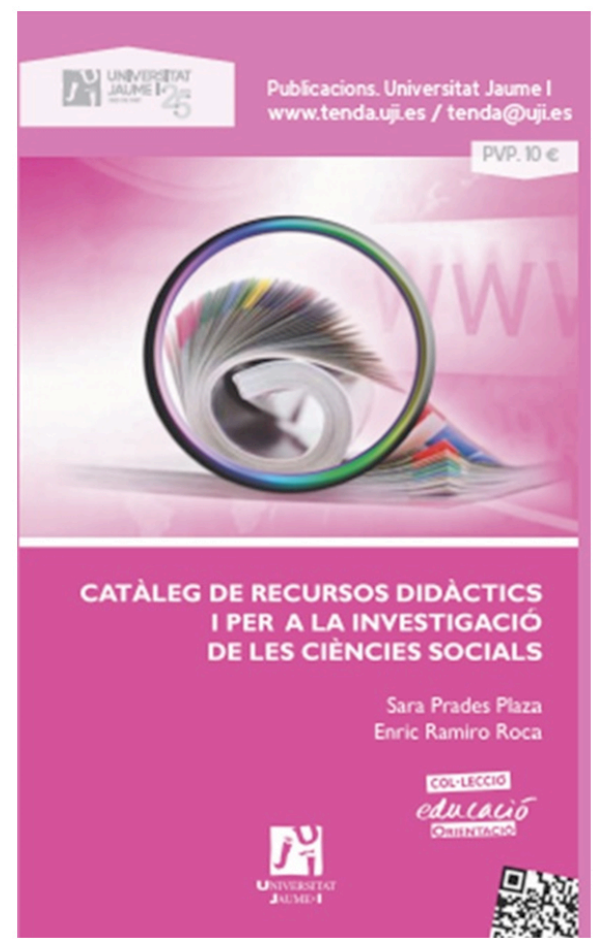

Figura 1. Coberta del Catàleg que recull els recursos didàctics de les CC. SS.

Per tot això, aquest llibret té com a objectiu principal justament el que indica el seu nom: oferir un ampli ventall de connexions molt seleccionades per a poder investigar i treballar en el camp de les Ciències Socials. El seu camp d'acció abraça des de l'educació infantil fins la universitat, amb matèries tan diverses com la Geografia, la Història i l'Art, passant per l'economia, la demografia o la cartografia entre altres.

La primera part se centra en les principals revistes en paper de l'Estat espanyol i alguns llibres molt seleccionats i bàsics. És la part més divulgativa. El segon bloc se centra ja completament en el món digital, oferint un conjunt de recursos per a qualsevol persona que vulga preparar-se les classes, oposicions, o fer treballs d'investigació bàsica o profunda.

El conjunt d'enllaços estan totalment actualitzats i estructurats per a facilitar la seua consulta al temps que s'orienta sobre el contingut de cadascun d'ells: recursos per a les classes, collectius i associacions, projectes internacionals, portals i projectes educatius, ONGs i organitzacions similars, periòdics i revistes digitals, cartografia i materials complementaris, recursos per a la investigació $\mathrm{i}$ jocs educatius.

A través d'aquest motor didàctic farcit de centenars de possibilitats, podrem guanyar molt de temps en les consultes que realitzem i aportar documentació actual i completa. Es tracta bàsicament d'una eina imprescindible tant per al treball quotidià com per a la necessària consulta esporàdica que ens obliga l'actualitat diària, i que es pot aconseguir fàcilment a través de qualsevol llibreria en format paper o digital 2.

\subsection{Materials sobre interculturalitat ${ }^{3}$}

L'objectiu bàsic d'aquest conjunt de materials ha estat donar a conèixer altres cultures per a crear una sensibilitat positiva cap a elles. Aquesta capsa conté sis jocs que tenen com a objectiu el contribuir a difondre la riquesa que representa una visió del món intercultural i crear lligams positius i actituds favorables cap a aquesta realitat.

Els noms dels jocs i les instruccions s'han redactat en tres llengües: valencià, castellà i anglès. També s'ha fet constar l'autoria de cada joc i un correu electrònic per a sollicitar més informació.

La seua edició ha estat possible gràcies a l'ajuda de I'Oficina de Cooperació al Desenvolupament i Solidaritat (OCDS) de la Universitat Jaume I de Castelló en la $6^{a}$ convocatòria d'ajudes per a projectes d'investigació i formació “OPI-UJl" Migració i Interculturalitat, any 2013, modalitat B, i molt especialment de l'editorial Babilonia i de Francisco Pérez Belda.

Cada joc disposa d'un quadernet que especifica: nom del joc, autoria, objectiu, material, funcionament, imatges, explicació matemàtica, instruccions, explicació dels continguts. Aquest material és complementari i la seua utilització no és imprescindible per a jugar. El principal

\section{2 Índex detallat: \\ 1. Revistes educatives}

1.1. Revistes d'educació infantil

1.2. Revistes d'educació primària

2. Llibres sobre recursos didàctics escolars i consells educatius

3. Webs sobre ciències socials o que tenen alguna secció

dedicada a les ciències socials

3.1. Recursos per a les classes

3.2. Recursos de collectius i associacions

3.3. Institucions i projectes internacionals amb informacions sobre ciències socials

3.4. Organismes estatals i regionals amb materials de ciències socials

3.5. Portals i projectes educatius

3.6. ONG i associacions similars amb materials educatius

3.7. Periòdics i revistes digitals

3.8. Cartografia i materials complementaris

3.9. Recursos per a la investigació.

3.10. Jocs didàctics

4. Codi OR, URL i clau.

3 Materials creats pel grup DIMPA (Didàctica de la Imatge i el Patrimoni) de la Universitat Jaume I de Castelló, dirigits per l'autor en els quals han participat els professors Sergi Selma, Sara Prades, i Ximo Aparici. 
Ramiro Roca, Enric; Gil Noé, José Vicente. “Imaginación y creatividad matemática en las ciencias sociales”. @tic. revista d'innovació educativa. Número 19. Otoño (Julio-Diciembre 2017), pp. 56-61.

valor dels jocs és gaudir del seu ús i que el seu contingut es vaja incorporant al pensament dels jugadors d'una forma subliminal. La carpeta de materials es titula "Els jocs de la pizza" (veure figura 2) i inclou sis activitats: Joc de les creences. Està dedicat a les principals creences $\mathrm{i}$ espiritualitats que $\mathrm{h}$ ha disseminades pel planeta, basat en la "Targeta màgica de punxa una beguda" ideat per Martin Gardner (Gardner, 2011).

Joc de les celebracions. Recull un conjunt de nou festes i tradicions dels cinc continents en format de targeta gran, basat en "La mansió embruixada" de David Copperfield (http://matematicas-

maravillosas.blogspot.com.es/2008/04/la-mansinembrujada-truco-televisiivo.html).

Joc dels instruments. Conté la imatge de dotze instruments de diferents continents i èpoques històriques, basat en un invent de Tom Hamilton (Gardner, 1992).

Joc dels paisatges. Ofereix vint-i-cinc imatges de distints entorns del planeta agrupats en paisatges de costa, planura, muntanya i urbans, basat en el principi dels forats negres (Alegria, 2008).

Joc de personatges de la península ibèrica. Està format per un pòster i un gran dau on apareixen els personatges seleccionats i tres cartons dissenyats per a construir un, basat en les targetes de números (Capó, 2012).

Joc de personatges de la resta del món. Està format per un pòster i un gran dau on apareixen els personatges seleccionats i tres cartons dissenyats per a construir un dau, basat en les targetes de números (Capó, 2012).

Tots els personatges, tant de la península ibèrica com de la resta del món, han estat seleccionats per una vintena de professors que imparteixen ciències socials a diferents instituts del País Valencià. Representen els personatges que més apareixen als llibres de text amb altres aportacions que complementen el camp científic, literari, oriental o valencià, entre altres. Es un material de reforç de l'assignatura i al mateix temps de crítica al seu contingut, doncs la immensa majoria són del gènere masculí, guerrers i dictadors.

Amb tot el material, pretenem oferir recursos lúdics, però també una forma diferent de transmetre unes informacions i valors que faciliten unes competències més lligades a la convivència i la justícia. Igualment, aquestes exemplificacions concretes es poden adaptar a multitud de possibilitats. Cadascun dels jocs va acompanyat d'un quadern d'instruccions i explicacions dels paisatges, personatges, creences, festes tradicions,... com hem esmentat anteriorment. Tan sols representen un complement i no són necessaris per a jugar. D'alguna manera serveixen de ganxo per a la curiositat que poden tindre i com a nexe per a futures investigacions a través de les TIC (tecnologies de la informació i la comunicació) i TAC (tecnologies de l'aprenentatge i el comportament).

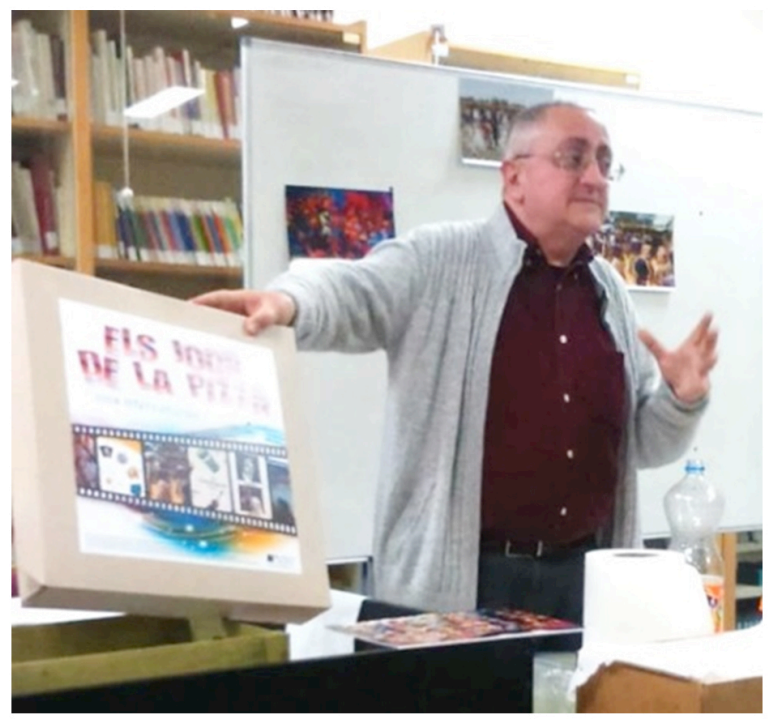

Figura 2. Presentació de la caixa "Els jocs de la pizza" i la seua coberta.

\subsection{Materials sobre la igualtat de gènere}

Segurament, si pensem o preguntem sobre dones científiques, ens apareixerà una curta enumeració. Tanmateix, la història de la ciència no es podria fer sense el seu treball, tot i que la immensa majoria dels seus noms han passat a l'oblit, s'han silenciat o esborrat conscientment.

En aquesta baralla, iniciada fa deu anys amb el simple objectiu de fer una relació de dones que destacaren en els diversos camps intellectuals, hem seleccionat 52 noms propis. Però en són moltes més i el gran problema que hem tingut al realitzar-la ha estat la seua selecció. Cada personatge consta de la seua imatge, lloc i data de naixement i defunció, i una breu síntesi que explica la seua importància.

El període investigat abraça des del s. XXVIII a.C. fins a l'actualitat amb I'única limitació que cap científica viu actualment. Evidentment és impossible poder destacar totes les dones que han excel.lit durant tots aquests segles i qualsevol selecció mai serà unànime. Tanmateix, ho hem intentat amb un equilibri, sempre inestable, entre les diferents ciències específiques, distribució geogràfica i cronològica, amb l'ajuda d'un selecte grup d'investigadors i investigadores.

Així doncs, hem intentat tindre en compte totes les civilitzacions però no ha estat possible. Malgrat la inestimable ajuda rebuda, la manca de documentació accessible sobre el món oriental i l'escassa presència de la dona en aquests àmbits fins a èpoques molt recents, ens han entrebancat l'objectiu proposat. Igualment, la gran dificultat per a aconseguir les imatges i la informació biogràfica ha marcat el resultat.

La baralla la formen els quatre pals: rombes o diamants, cors, trèvols i piques; cadascun amb tretze cartes, i repartits per igual entre els dos gèneres. Una reflexió separada cal fer sobre els comodins. N'hem seleccionat dues imatges com a representants collectiu de dues concepcions de diferent cronologia, espai geogràfic, i visió cultural i religiosa: per un costat, l'Escola Pitagòrica de Cretona i, per un altre, la Casa de la Saviesa de Bagdad.

Malgrat les bones intencions, som conscients que no ho haurem aconseguit a gust de totes i tots. La importància dels personatges mostrats és indiscutible, però les 
Ramiro Roca, Enric; Gil Noé, José Vicente. “Imaginación y creatividad matemática en las ciencias sociales”. @tic. revista d'innovació educativa. Número 19. Otoño (Julio-Diciembre 2017), pp. 56-61.

comparacions són inevitables i les opinions de cadascú molt valuoses. Les cartes es poden utilitzar per a qualsevol joc de la baralla francesa o espanyola com al pòquer, el mus, el cinquet, o la brisca entre altres; i per a trucs de màgia o matemàgia, si s'escau. Esperem que la lectura dels personatges i la seua utilització ens ajude a conéixer millor la història de la ciència i a tindre una visió més completa i justa de la seua evolució. També desitgem que el seu ús done més d'una sorpresa, i una visió més enriquida i completa que facilite una millor convivència.

El material que hem explicat, es complementa amb un quadernet titulat: 50 jocs automàtics (Didàctica de la cartografia matemàtica). Es tracta d'un recopilatori de mig centenar de rutines que es poden fer sense cap tipus de preparació, que tenen tots una fonamentació matemàtica i una posada en escena espectacular i senzilla. La seua experimentació i el llenguatge instructiu i divulgatiu utilitzat, tenen com a objectiu en convertir aquest material es un recurs de fàcil accés a qualsevol persona que domine mínimament la lectoescriptura.

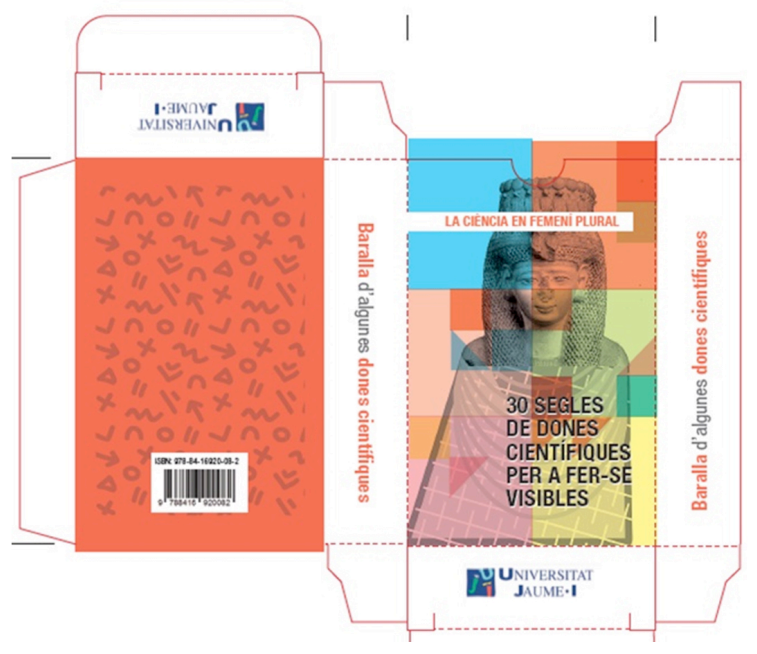

Figura 3. Caixa de la baralla de cartes sobre algunes dones científiques.

\section{Experimentació i resultats}

Els materials s'han experimentat en diversos centres de primària, secundària i en el grau de mestre d'educació primària de la Universitat Jaume I de Castelló (UJI), així com a diferents universitats de la xarxa Lluís Vives com la UIB a Palma, UB a Barcelona, la UdeG a Girona, la universitat Roviri i Virgili a Tarragona, la UV a València, la UdL de Lleida, la UA d'Alacant; i també a la UM a Múrcia, en Màsters de secundària, cursos de magisteri, i cursos de Cefire per a mestres i professors. Totes les valoracions han estat molt positives. Durant aquesta fase, s'han mostrat, explicat i utilitzat els jocs.

En una segona fase que encara no hem iniciat encara, està previst que els participants manipulen les diferents propostes per a crear nous recursos a partir d'aquesta base, potenciant la creativitat i la imaginació, al temps que es contextualitzen. El format serà en tallers i es regalarà una maleta a la biblioteca de cada universitat ${ }^{4}$.

\footnotetext{
${ }^{4}$ Fins al 2017, únicament està la maleta amb els jocs de la pizza a les biblioteques de la Universitat Jaume I de Castelló i de la Universitat de Barcelona, al campus de Mundet.
}

En una tercera fase, està prevista la difusió dels materials i continguts a través del Cefires del País Valencià i escoles d'estiu que ho solliciten, mitjançant un conjunt de maletes que estaran en dipòsit a la biblioteca de I'UJI. Seria ideal poder disposar de més exemplars per a la seua difusió, però considerem que serà impossible o molt complicat degut a la diversitat de materials que la conformen i el seu cost econòmic. És per això que hem optat per la seua utilització com a exemple i base d'altres possibilitats que contextualitze cada grup o entitat que l'experimente.

Confiem que aquests materials puguen contribuir a una millor convivència entre cultures i civilitzacions, a través dels recursos de ciències socials amb una base matemàgica. Igualment, esperem que entitats i grups aprofiten la investigació que hem realitzat durant aquests anys de forma totalment gratuïta per a benefici de la societat en general.

\section{Referències}

Alegría, P. (2008) Magia por principios. Autoedición.

Aparici, J.; Ramiro, E. (2015) Quin instrument prefereixes? Els jocs de la pizza. Interculturalitat $i$ ciències socials. Navarrés: Babilonia. Asociación Cultural.

Añó. R.; Ramiro, E. (2015a) Em coneixes? Joc dels personatges peninsulars. Els jocs de la pizza. Interculturalitat $i$ ciències socials. Navarrés: Babilonia, Asociación Cultural.

Añó. R.; Ramiro, E. (2015b) Em coneixes? Joc dels personatges universals. Els jocs de la pizza. Interculturalitat $i$ ciències socials. Navarrés: Babilonia, Asociación Cultural.

Baena, J. (1997) "Arqueología experimental, algo más que un juego", BAEX: Boletín de Arqueología Experimental, $1, \quad$ pp.4-5. https://revistas.uam.es/index.php/arqexp/article/vie w/5809

Capel, H.; Urteaga, L. (1991) Las nuevas geografías. Barcelona: Salvat.

Capó, M. (2012) Magia matemática. Barcelona: Ediciones B.

Coma, L.; Santacana, J. (2010) Ciudad educadora y patrimonio. Gijón: Trea.

Cuenca, J. M.; Domínguez, C. (2001) "La Didáctica de las Ciencias Sociales en los programas de difusión del patrimonio urbano. Los museos de ciudad" en Estepa, J; Domínguez, C. y Cuenca, J.M. (eds.), Museo y patrimonio en la didáctica de las Ciencias Sociales. Huelva: Universidad de Huelva.

Cuenca, J. M.; Martín, M.J. (1999) "La excavación arqueológica: un centro de interpretación y difusión patrimonial. Una experiencia en el casco histórico de Huelva", Aula. Historia Social, 4, pp.88-94.

Gardner, M. (1992) Magia inteligente. Madrid: Zugarto Ediciones.

Gardner, M. (2011) Matemáticas, magia y misterio. Barcelona: RBA.

Guzmán, M. (1997) "Matemáticas y sociedad. 
Ramiro Roca, Enric; Gil Noé, José Vicente. “Imaginación y creatividad matemática en las ciencias sociales”. @tic. revista d'innovació educativa. Número 19. Otoño (Julio-Diciembre 2017), pp. 56-61.

Acortando distancias", Números, 32, pp.3-11. http://www.sinewton.org/numeros/numeros/32/Artic ulo01.pdfb

Hernández, A. (2010). http://granalexander.com/. Consultat el 26-12-2016 https://www.youtube.com/watch?v=ywCbQYwcZR U

Prades, S. i Ramiro, E. (2015) El joc de les creences. Els jocs de la pizza. Interculturalitat i ciències socials. Navarrés: Babilonia, Asociación Cultural.

Prats, J.; Santacana, J. (2009) "Ciudad, educación y valores patrimoniales. La ciudad educadora, un espacio para aprender a ser ciudadanos", íber. Didáctica de las Ciencias Sociales, Geografía e Historia, 59, pp.8-21.

Ramiro, E. (2014) "Mozart i el parxís" en López, R. (Ed.). Actes de la XV Assemblea d'Història de la Ribera. La música a la Ribera del Xúquer. Benimodo: Ajuntament de Benimodo.

Ramiro, E. (2017) "Las matemáticas nos alegrarán la cara" , UNO. Revista de Didáctica de las Matemáticas, 76, pp.51-56.
Segarra, LI. (2006) Els millors jocs de matemàgica. Barcelona: Mina.

Selma, S. i Ramiro (2016) Quin paisatge apadrines?. Joc dels paisatges. Els jocs de la pizza. Interculturalitat $i$ ciències socials. Navarrés: Babilonia, Asociación Cultural.

Selma, S.; Ramiro, E. (2016) T'animes a celebrar-ho? Joc de les festes i tradicions. Els jocs de la pizza. Interculturalitat $i$ ciències socials. Navarrés: Babilonia, Asociación Cultural.

Vinuesa, C. (2011) "MatemáGicas", Números, 76, pp.31-46.

http://www.sinewton.org/numeros/numeros/76/Mon ografico 02.pdf

| Cita recomendada de este artículo

Ramiro Roca, Enric; Gil Noé, José Vicente. (2017). “Imaginación y creatividad matemática en las ciencias sociales”. en @tic. revista d'innovació educativa. Número 19. Otoño (Julio-Diciembre 2017), pp. 56-61. 